
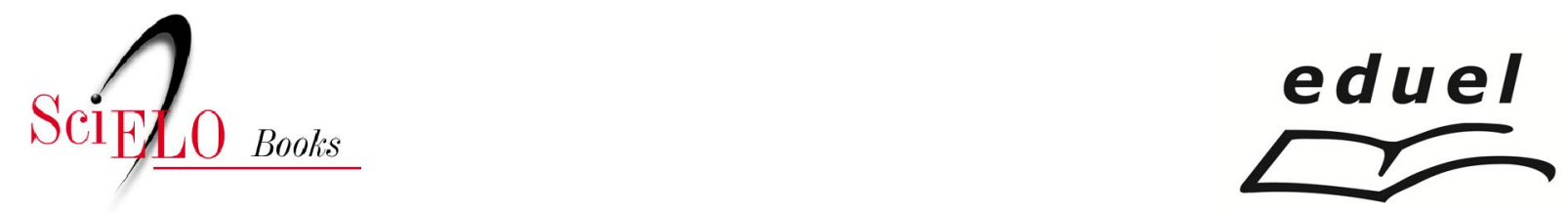

\title{
Patogenia da toxoplasmose congênita
}

\author{
Regina Mitsuka-Breganó \\ Fabiana Maria Ruiz Lopes-Mori \\ Italmar Teodorico Navarro \\ (orgs.)
}

\section{SciELO Books / SciELO Livros / SciELO Libros}

MITSUKA-BREGANÓ, R., LOPES-MORI, FMR., and NAVARRO, IT., orgs. Toxoplasmose adquirida na gestação e congênita: vigilância em saúde, diagnóstico, tratamento e condutas [online]. Londrina: EDUEL, 2010. Patogenia da toxoplasmose congênita. pp. 9-14. ISBN 978-85-7216-676-8. Available from SciELO Books $<$ http://books.scielo.org $>$.

\section{(1) (1) $\Theta(9)$}

All the contents of this work, except where otherwise noted, is licensed under a Creative Commons Attribution-Non Commercial-ShareAlike 3.0 Unported.

Todo o conteúdo deste trabalho, exceto quando houver ressalva, é publicado sob a licença Creative Commons Atribuição Uso Não Comercial - Partilha nos Mesmos Termos 3.0 Não adaptada.

Todo el contenido de esta obra, excepto donde se indique lo contrario, está bajo licencia de la licencia Creative Commons Reconocimento-NoComercial-CompartirIgual 3.0 Unported. 


\section{Patogenia da toxoplasmose congênita}

Na toxoplasmose congênita, o parasita atinge o concepto por via transplacentária causando danos com diferentes graus de gravidade dependendo dos fatores como virulência, cepa do parasita, da capacidade da resposta imune da mãe e também do período gestacional em que a mulher se encontra, podendo resultar em morte fetal ou em graves sintomas clínicos. (DUNN et al., 1999). Assim sendo, o acompanhamento sorológico deveria ser periódico durante toda a gestação nas mulheres soronegativas, buscando o diagnóstico de uma possível primoinfecção. (VIDIGAL et al., 2002).

Vários estudos demonstraram que o risco de infecção fetal aumenta com a idade gestacional, porém, a gravidade das sequelas diminui com ela, sendo as formas subclínicas neonatais próprias da infecção no terceiro trimestre da gestação. (DESMONTS; COUVREUR, 1974; HOHLFELD et al., 1994). Portanto, a gravidade é inversamente proporcional ao tempo de 
gestação e a facilidade de transmissão é diretamente proporcional ao mesmo tempo. Por outro lado, as lesões oculares não são totalmente dependentes da época da infecção e podem ocorrer casos graves de retinocoroidite mesmo em infecções adquiridas pela mãe na segunda metade da gestação. (GILBERT et al., 2008).

A taxa de transmissão transplacentária e o risco de desenvolvimento de sinais clínicos podem variar em gestantes não tratadas e de diferentes regiões. A tabela 1 sumariza os resultados obtidos por Dunn et al. (1999) em um estudo realizado na França onde o acompanhamento sorológico de gestantes negativas é mensal e, consequentemente, o tratamento materno é precoce.

Tabela 1 - Taxa de transmissão transplacentária e risco de desenvolvimento de sinais clínicos da toxoplasmose de acordo com a idade gestacional em que ocorreu a primoinfecção.

\begin{tabular}{|c|c|c|}
\hline $\begin{array}{l}\text { Idade gestacional na qual } \\
\text { ocorreu a soroconversão } \\
\text { (semanas) }\end{array}$ & $\begin{array}{l}\text { Transmissão transpla- } \\
\text { centária* } \\
(\%)\end{array}$ & $\begin{array}{l}\text { Risco de a criança desenvolver } \\
\text { sinais clínicos antes dos três } \\
\text { anos de idade (\%) }\end{array}$ \\
\hline 12 & 6 & 75 \\
\hline 16 & 15 & 55 \\
\hline 20 & 18 & 40 \\
\hline 24 & 30 & 33 \\
\hline 28 & 45 & 21 \\
\hline 32 & 60 & 18 \\
\hline 46 & 70 & 15 \\
\hline 40 & 80 & 12 \\
\hline
\end{tabular}

Fonte: Pinard, Leslie e Invine (2003). Adaptada de Dunn et al. (1999).

* O diagnóstico da infecção fetal foi baseado em exames de amniocentese com mais de quatro semanas após a soroconversão materna.

Alguns autores consideram que o período gestacional mais crítico ocorre entre a $10^{\mathrm{a}}$ e $26^{\mathrm{a}}$ semanas, momento em que a placenta já é grande para se infectar e, ao mesmo tempo, o feto é imaturo e pode sofrer danos importantes. (DUNN et al., 1999; MARTíN, 2004). 
Como resultado da infecção intrauterina, a toxoplasmose neonatal varia em severidade no quadro clínico apresentado, do assintomático ao fatal. Segundo Frenkel (2002), de acordo com o trimestre gestacional da primoinfecção materna, a patogenicidade pode ser:

a) Infecção materna no primeiro trimestre de gestação: normalmente ocorre morte fetal;

b)Infecçãomaternanosegundoeterceirotrimestres degestação:podeocorrerprematuridade e ocasionar a chamada tétrade de Sabin: microcefalia, retinocoroidite, calcificações cerebrais e deficiência mental. (SABIN, 1942). O feto pode apresentar hidrocefalia, resultado da estenose do aqueduto acompanhada, frequentemente, de obstrução da drenagem do sistema periventricular, necrose periventricular com macro ou microcefalia (em 50\% dos casos), acentuada destruição da retina, retinocoroidite (em $90 \%$ dos pacientes com infecção), calcificações cerebrais (em 69\%) e retardo mental ou perturbações neurológicas (em $60 \%$ dos casos), com sinais de encefalite com convulsões. O recém-nascido também pode apresentar lesões iniciais como nódulos miliares disseminados por todo o encéfalo, ou em torno de focos necróticos; os ventrículos cerebrais podem estar dilatados e as lesões cerebrais podem se calcificar (Figuras 2, 3, 4 e 5). Outras alterações oculares ainda podem acontecer como graus variáveis de degeneração e edema de retina, lesões vasculares da coroide, neurite óptica, microftalmia, nistagmo, estrabismo e iridociclite (Figuras 6, 7 e 8).

$\mathrm{Na}$ maioria das vezes, no momento do nascimento, as infecções congênitas são assintomáticas, porém, podem apresentar sequelas que se manifestam em algum momento da vida, principalmente complicações oculares e do sistema nervoso central. Muitos casos de retinocoroidite têm como causa a toxoplasmose congênita. (BEVERLEY, 1973).

De acordo com Wilson et al. (1980), entre os recém-nascidos infectados e assintomáticos, acima de $85 \%$ desenvolvem retinocoroidite durante a infância ou adolescência e $40 \%$ apresentam sequelas neurológicas. 


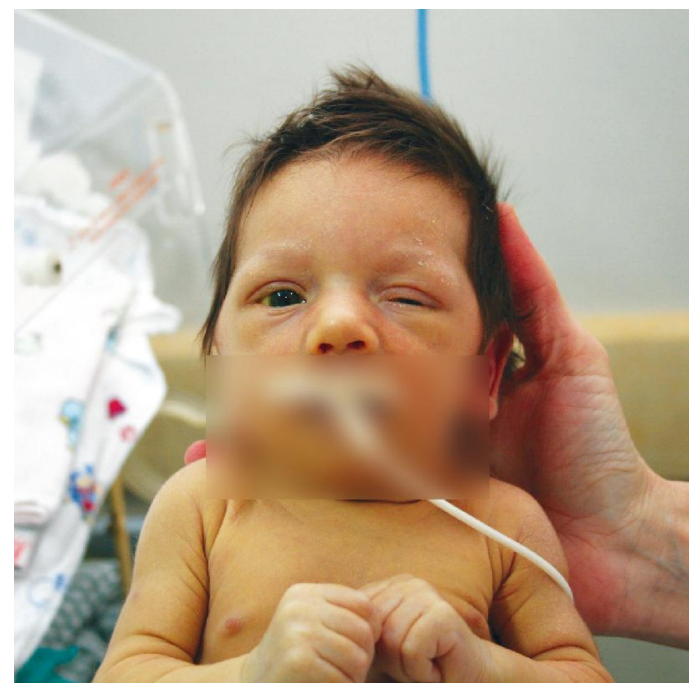

Figura 2: Lactente com toxoplasmose congênita, apresentando microcefalia e ptose palpebral à esquerda. A mãe não foi tratada durante a gestação.

Fonte: Dra. Jaqueline Dario Capobiango

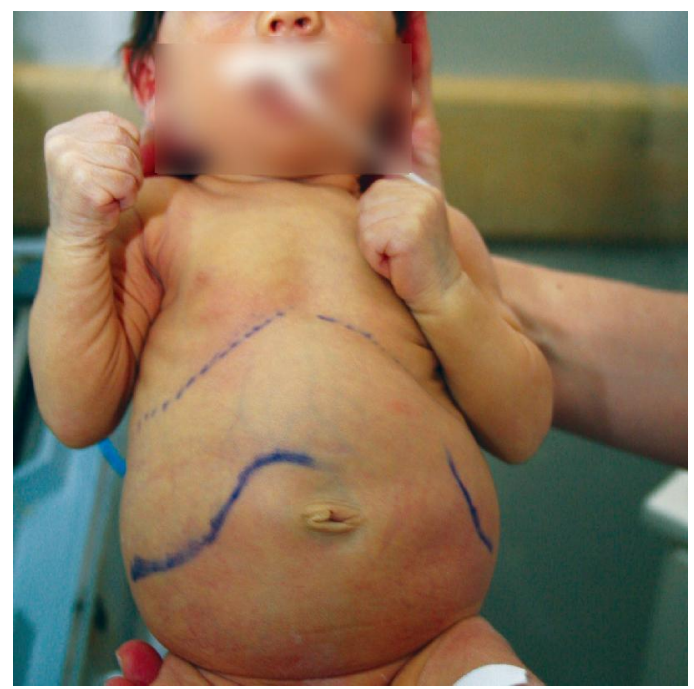

Figura 3: Mesmo paciente apresentando icterícia, hepatomegalia e esplenomegalia. Fonte: Dra. Jaqueline Dario Capobiango 


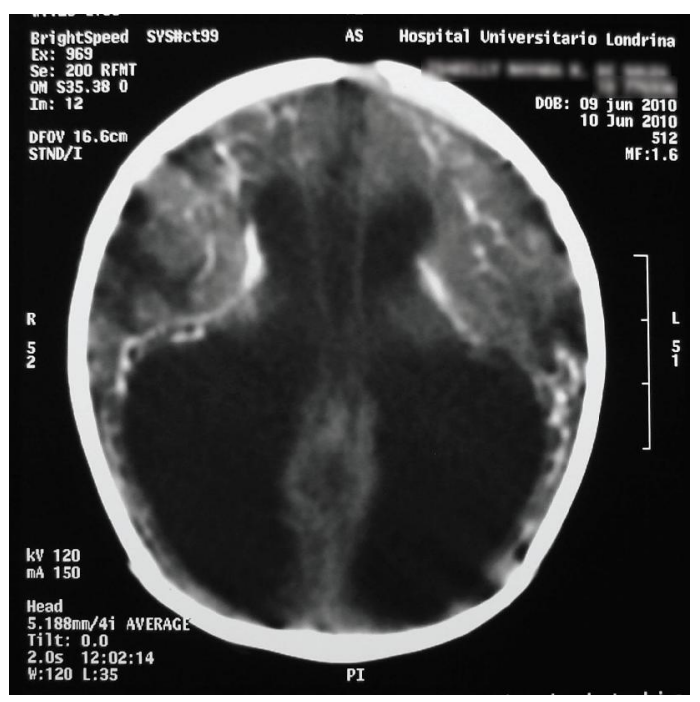

Figura 4: Tomografia Computadorizada do mesmo paciente mostrando dilatação ventricular importante e áreas de encefalomalácia.

Fonte: Dra. Jaqueline Dario Capobiango
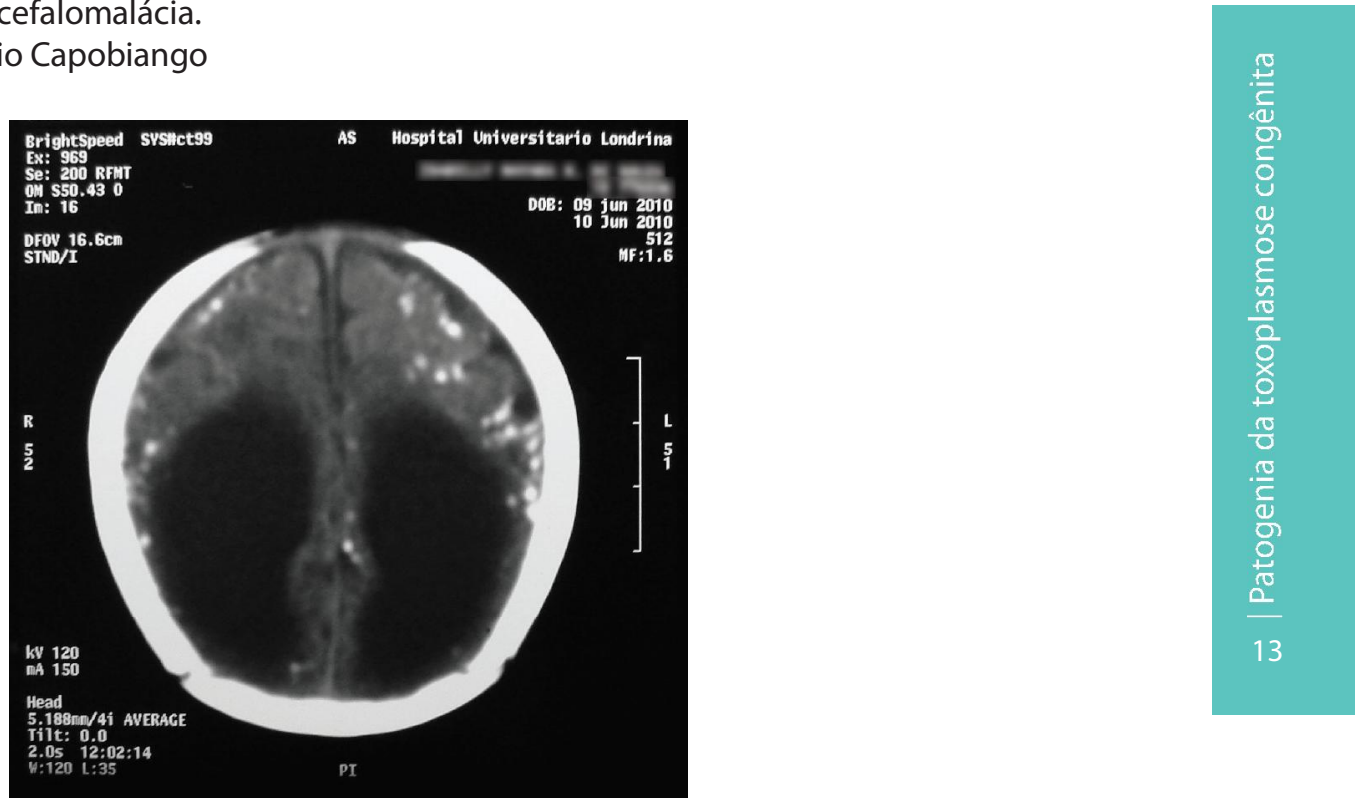

Figura 5: Tomografia Computadorizada do mesmo paciente mostrando hidrocefalia e múltiplas calcificações cerebrais.

Fonte: Dra. Jaqueline Dario Capobiango 


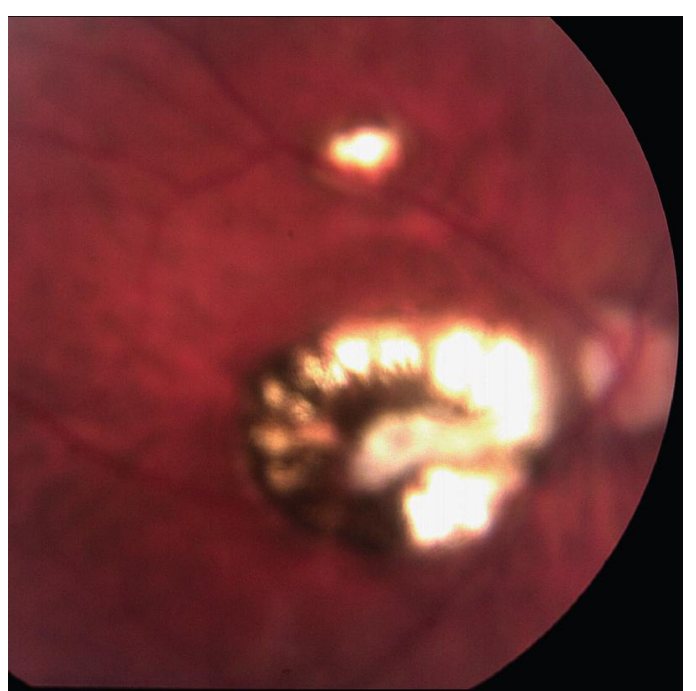

Figura 6: Paciente com toxoplasmose congênita e acometimento macular.

Fonte: Dr. Antonio Marcelo Barbante Casella.

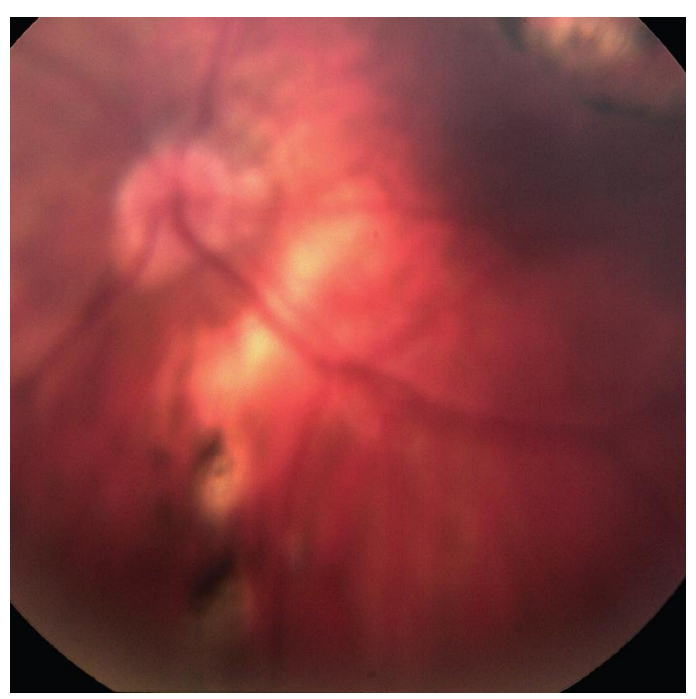

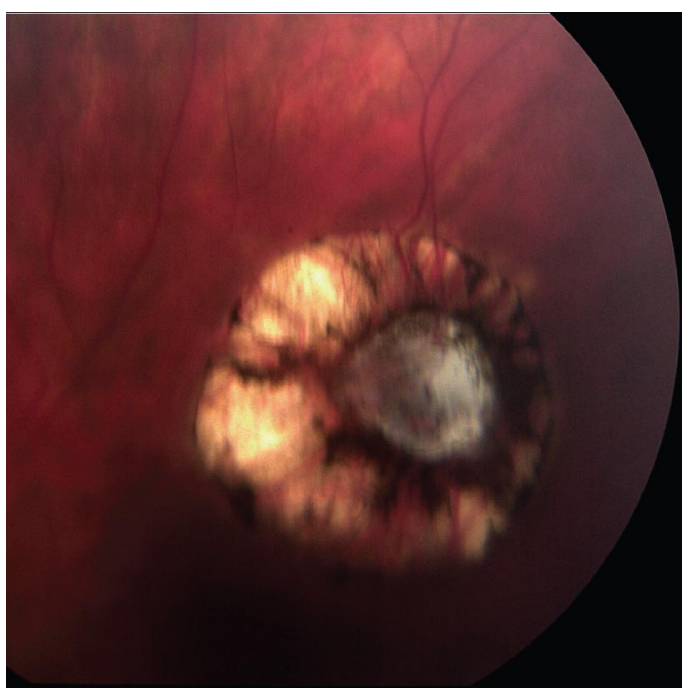

Figura 7: Foco de retinocoroidite cicatrizado em periferia de retina em paciente com toxoplasmose congênita.

Fonte: Dr. Antonio Marcelo Barbante Casella.

Figura 8: Paciente com vários focos de toxoplasmose. Felizmente poupando a área macular. Fonte: Dr. Antonio Marcelo Barbante Casella. 